\title{
Biocompatibilidad de Células Madres Mesenquimales de Tejido Gingival Humano en Cultivo con un Andamiaje de Polímero Sintético de Ácido Poliláctico (OPLA)
}

\author{
Biocompatibility Of Mesenchymal Stem Cells Derived From Human Gingival Tissue In Culture \\ With A Scaffold Of A Synthetic Polymer Open Porosity Polylactic Acid Polymer (OPLA)
}

\author{
Claudia Brizuela Cordero*; Nicole Saint Jean* \& Carolina Inostroza Silva*
}

BRIZUELA, C. C.; SAINT, J. N. \& INOSTROZA, S. C. Biocompatibilidad de células madres mesenquimales de tejido gingival humano en cultivo con un andamiaje de polímero sintético de ácido poliláctico (OPLA). Int. J. Morphol., 32(3):767-772, 2014.

RESUMEN: La ingeniería tisular se plantea como tratamiento ideal para la regeneración de tejidos con la utilización de andamiajes, células madres y factores de crecimiento. Las células madres de origen gingival plantean ventajas de obtención, mientras que el OPLA 3D permite cultivos de alta densidad celular. El objetivo de esta investigación fue evaluar la biocompatibilidad de células madres de origen gingival en OPLA. Las células se obtuvieron de tejido gingival y fueron caracterizadas fenotípica y funcionalmente. La biocompatibilidad se evaluó mediante la proliferación celular, prueba de viabilidad con azul tripán y diferenciación celular a linaje condrogénico y osteogénico. El recultivo del constructo se utilizó para evaluar la capacidad de transporte. Las células al interior del OPLA se visualizaron mediante cortes teñidos con H-E. Las células madres mesenquimales en OPLA proliferaron, 80\% de confluencia a la cuarta semana. La viabilidad celular en OPLA fue de 83,32\%. En el recultivo, las células comienzan a proliferar a la semana. El OPLA permite la diferenciación celular a linaje condrogénico y osteogénico. Se observan células al interior del OPLA, permite la proliferación, viabilidad y diferenciación celular. El OPLA podría ser utilizado como andamiaje celular para la ingeniería de tejidos.

PALABRAS CLAVE: Células madre mesenquimales; Tejido conectivo gingival; Biocompatibilidad.

\section{INTRODUCCIÓN}

Los componentes claves para la ingeniería de tejidos son las células madres, factores de crecimiento y andamiajes (Saber et al., 2009). Las células madres son un grupo específico de células indiferenciadas que tienen un potencial proliferativo elevado y que presentan dos características fundamentales: tienen la habilidad de dividirse continuamente para replicarse en ellas mismas (auto-replicación) y pueden producir células especializadas que se logran diferenciar en otros tipos de células o tejidos (diferenciación en multilinaje) (Dominici et al., 2006). A la fecha, seis tipos de células madres mesenquimales (CMM) dentales humanas se han aislado y caracterizado: células madres de la pulpa dental (DPSCs), células madres de dientes temporales exfoliados (SHED), células madres de la papila apical (SCAP), células madres del ligamento periodontal (PDLSCs), células madres del folículo dental (DFSC) y células madres de tejido conectivo gingival humano (CMMg) (Friedlander et al., 2009; Mitrano et al., 2010; Thomson \& Kahler, 2010; Yen \& Yelick, 2011; Bansal \& Bansal, 2011; Brizuela et al., 2013).
Estudios in vitro e in vivo han demostrado que los factores de crecimiento pueden mejorar la capacidad de la regeneración tisular, quimioatracción, diferenciación y proliferación (Kaigler et al., 2006).

Otro componente esencial de la ingeniería tisular son los andamiajes. Estos tienen que proveer un microambiente físico-químico y biológico tridimensional. Debe permitir la unión, proliferación y diferenciación de las células madres sembradas en él. Además, debe permitir el paso de aire y tener la porosidad adecuada para el flujo de proteínas y factores de crecimiento (Rekow, 2003; Scheller et al., 2009; Qian et al., 2013).

OPLA es un andamiaje de polímero sintético que es sintetizado a partir de D, D-L, L ácido poliláctico. Este material tiene una estructura abierta 3D la cual es efectiva para cultivar células de alta densidad. Estos proveen un sustrato adhesivo que sirve como un soporte físico tridimensional para un cultivo de células in vitro como también para la re- 
generación tisular in vivo (Alexander et al., 2007, 2008; Linnes et al., 2007; Di Felice et al., 2009, 2010).

Las CMMg presentan ventajas en lo que se refiere a la fácil obtención del explante. Por lo tanto nuestro objetivo fue evaluar la biocompatibilidad de células madres de origen gingival en OPLA.

\section{MATERIAL Y MÉTODO}

Purificación y cultivo de CMM derivadas de tejido gingival humano. En el Centro de Salud de la Facultad de Odontología de la Universidad de los Andes se sometió a donantes jóvenes sanos a a anestesia local sin vaso constrictor, para luego extraer el trozo de tejido de $2 \times 2 \times 2 \mathrm{~mm}$ mediante una técnica atraumática, con la utilización de bisturí estéril $\mathrm{N}^{\circ} 15$. El explante de encía se colocó en $3 \mathrm{~mL}$ de PBS $1 \mathrm{X}$ (buffer fosfato salino) y $1 \mathrm{~mL}$ de Penicilina/ Estreptomicina (GIBCO, Invitrogen) para ser transportada al laboratorio. La obtención y la manipulación de las muestras humanas se realizó bajo las consideraciones exigidas por el Comité de Bioética de la Universidad de los Andes.

Los explantes fueron cultivados en placas de cultivo con un medio completo compuesto por a-MEM (Minimal Eagle Medium, Invitrogen), 20\% de suero fetal bovino (SFB), (Suero Fetal Bovino, HyClone) y 1\% de Antibiótico (Penicilina-Estreptomicina, Pen Strep, Invitrogen). A los 10 días se realizó el cambio de medio y el explante fue eliminado.

A las 4 semanas de seguimiento de los cultivos, se observaron las primeras células con fenotipo fibroblastoide adheridas al plástico. Obtenidas las células, se resuspendieron en $3 \mathrm{~mL}$ de medio completo, se contaron en una cámara de Neubauer (Neubauer Improved Pright Line, 0,1 mm de profundidad, $0,0025 \mathrm{~mm}^{2}, \mathrm{HBG}$ ) y se sembraron en flask de 25 $\mathrm{mL}$ a una concentración de 10.000 cels $/ \mathrm{cm}^{2}$.

Se cultivaron durante 3 semanas hasta alcanzar la confluencia cercana al $80 \%$ y se tripsinizaron con $1 \mathrm{~mL}$ de Tripsina (TrypLE ${ }^{\mathrm{TM}}$ Select, Invitrogen) durante 5 minutos a $37^{\circ} \mathrm{C}$, para posteriormente, lavar en solución fosfatada tamponada PBS $1 \mathrm{x}$ (Hyclone) y centrifugar a $1.680 \mathrm{rpm}$ por 5 minutos a temperatura ambiente. De este modo las CMM entran al pasaje 1. Se cultivaron hasta el pasaje 4 para la caracterización celular y realización de los ensayos funcionales.

Caracterización de CMM derivadas de tejido gingival. Para la caracterización in vitro se consideraron los criterios publicados según Dominici et al.: adherencia al plástico, proliferación, morfología fibroblastoide y diferenciación a linaje condrogénico, osteoclastogénico y adipogénico (Tokalov et al., 2007). Las diferenciaciones a multilinaje se realizaron según protocolos descritos en el Technical Manual, StemCell Technologies (2008), versión 1.2.0 (Becerra et al., 2012).

Inmunofenotipo de CMM. La inmunotipificación de las CMM en pasaje 4 fue realizada mediante citometría de flujo utilizando anticuerpos conjugados con fluorescein isothiocyanate-(FITC), phycoerytrin-(PE) o peridinin chlorophyll protein (PerCP): anti-CD34 (BeckmannCoulter), anti-CD45 (BeckmannCoulter), antiCD73 (BDPharmingen), anti-CD90 (BDPharmingen) y antiCD105 (Caltag). La adquisición y análisis de las muestras fue realizada utilizando un citómetro de flujo marca Coulter Epics-XL (Coulter Corporation, Florida, USA).

Ensayos de Diferenciación. Las CMM en pasaje 4 y con una confluencia del $80 \%$ fueron sembradas en 3 placas diferentes, para la inducción hacia la diferenciación adipogénica,osteogénica y condrogénica y CMM sin medios de inducción. Durante la diferenciación se realizaron cambios de medio fresco de inducción cada 4 días. La duración del proceso varió según el linaje celular. Se realizaron tinciones específicas indicadoras de la diferenciación y se registraron fotos en microscopio óptico de luz invertido con contraste de fase Olympus CKX41.

A. Diferenciación Osteogénica: Se sembraron células en una densidad de $35.000 \mathrm{cel} / \mathrm{cm}^{2}$ en placas de 4 pocillos. Se incubaron en la estufa a $37^{\circ} \mathrm{C}$ con $5 \% \mathrm{CO}_{2}$ toda la noche. $\mathrm{Al}$ día siguiente, se observaron las células al microscopio óptico. Al alcanzar el 100\% de confluencia, se agregaron 500 $\mathrm{ml}$ de medio de diferenciación con alfa-MEM, SFB 10\%, Penicilina y Estreptomicina (1\%), dexametasona $(0,1 \mu \mathrm{M})$, B-Glicerofosfato $(10 \mathrm{Mm})$, ascorbato-2 fosfato $(50 \mathrm{mg} / \mathrm{ml})$. Este último se agregó día por medio durante todo el proceso de diferenciación. Se mantuvieron incubadas en estufa a $37^{\circ} \mathrm{C}$ con 5\% de $\mathrm{CO}^{2}$ durante todo el proceso. Cuando se observaron cúmulos de minerales y cristales birrefringentes al microscopio (al cabo de 4 semanas), se detuvo la diferenciación y las células se tiñeron con solución Alizarin Red 40 mM en NaH2PO4 0,1 M pH 4,3 (Sigma). Las células en las placas fueron lavadas 2 veces con $0,25 \mathrm{~mL} / \mathrm{cm}^{2}$ de PBS $1 X$ y fijadas con $0,25 \mathrm{~mL} / \mathrm{cm}^{2}$ de etanol $70 \%$ (v/v) por $30 \mathrm{minu}-$ tos a temperatura ambiente. Luego las células fueron lavadas 2 veces con PBS $1 X$, agregándoseles $0,25 \mathrm{~mL} / \mathrm{cm}^{2}$ de Alizarin Red $40 \mathrm{mM}$ por 10 minutos a temperatura ambiente. Las células fueron nuevamente lavadas 2 veces con PBS $1 \mathrm{X}$ y finalmente se lavaron 5 veces con agua bidestilada.

B. Diferenciación Condrogénica: Se sembraron células en 
una densidad de $30.000 \mathrm{cel} / 10 \mu \mathrm{L}$ en forma de microgota en placas de 4 pocillos, para lograr la formación de micromasa, se incubaron por una hora y media para luego agregarles el medio de diferenciación especifico con alfa- MEM, SFB $10 \%$, Penicilina y Estreptomicina (1\%), Dexametasona $(0,1$ $\mu \mathrm{M})$, Insulina (5 $\mu \mathrm{g} / \mathrm{ml})$, TGF- Beta $1(10 \mathrm{ng} / \mathrm{ml})$, ascorbato-2-fosfato $(50 \mu \mathrm{g} / \mathrm{ml})$. Estos dos últimos se agregaron día por medio durante todo el proceso de diferenciación. A las 2 semanas se verificaron micromasas celulares y se detuvo la diferenciación. Estas fueron teñidas mediante Safranina O, preparando una solución de safranina $\mathrm{O}$ al $0,1 \% \mathrm{p} / \mathrm{v}$. Las células fueron lavadas $1 \mathrm{vez}$ con PBS $1 \mathrm{X}$ y luego fijadas con $0,15 \mathrm{~mL} / \mathrm{cm}^{2}$ de etanol al $70 \% \mathrm{v} / \mathrm{v}$ por 10 minutos. Se lavaron con PBS $1 \mathrm{X}$ para luego agregar $0,15 \mathrm{~mL} / \mathrm{cm}^{2}$ de safranina por 5 minutos a temperatura ambiente. Posteriormente fueron lavadas 5 veces con $0,15 \mathrm{~mL} / \mathrm{cm}^{2}$ de etanol absoluto (100\%) y por 5 veces con agua bidestilada.

Cultivo de CMMg en presencia de OPLA. En una placa de 96 pocillos $\left(\right.$ Nunc $\left.^{\mathrm{TM}}\right)$, se colocaron trozos de OPLA $(2 \times 2$ $\mathrm{mm} ; \mathrm{n}=10$ ) previamente humedecido con $200 \mathrm{~mL}$ de medio completo, se llevó a la estufa de cultivo para homologar las condiciones de cultivo de las células, por 30 minutos a $37^{\circ} \mathrm{C}$ con aire humidificado y $5 \%$ de $\mathrm{CO}^{2}$. Después se añadieron 100.000 CMM $/ \mathrm{cm}^{2}$. Los controles consistían en 10 pocillos con OPLA en $200 \mathrm{~mL}$ de medio completo y 10 pocillos 100.000 CMM/ $\mathrm{cm}^{2}$ en $200 \mathrm{~mL}$ de medio completo. Se cambió el medio completo cada 2 días (BD Three Dimensional OPLA Scaffold Catalog No. 354614 Guidelines for Use).

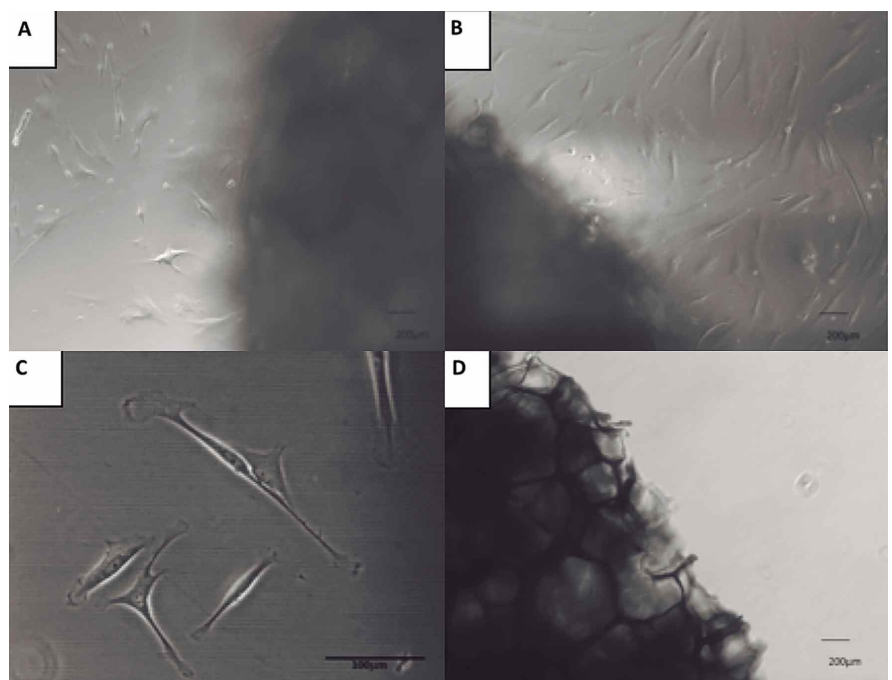

Fig. 1. Células madres mesenquimales derivadas de tejido gingival en cultivo con OPLA. (A) CMMg a la cuarta semana de cultivo se observan fuera del OPLA. (B) CMMg proliferando cerca de $70 \%$ de confluencia celular, después de cuatro semanas en cultivo. Microscopia óptica, magnificación 20X. (C) CMMg en cultivo característico fenotipo fibroblastoide. (D) OPLA en cultivo, característica estructura 3D celda abierta. Microscopia óptica, magnificación 40X.
Prueba de Azul tripán. La viabilidad se determinó por la técnica de exclusión vital, o sea, exclusión de las células no teñidas por el azul de tripán A la tercera semana de cultivo de las CMM en OPLA ( $\mathrm{n}=5), 10 \mu \mathrm{L}$ células tripsinizadas se les agregó $10 \mu \mathrm{L}$ de azul de tripán. Las células se depositaron para conteo en una cámara hemocitométrica de Neubauer. La lectura fue realizada por microscopia de luz y el cálculo del número de células/mL fue determinado por la siguiente fórmula: V x FN x FT/\#Q, en la cual: V= número de células viables contadas; $\mathrm{FN}$ = factor de la cámara de Neubauer $\left(10^{4}\right) ; \mathrm{FT}=$ factor de dilución del azul de tripan y \#Q = número de cuadrantes de la cámara utilizados para el recuento. El porcentaje de viabilidad celular se calculó aplicando la ecuación: V x 100/NT, en la que: NT = número total de células (viables y no viables) contadas en la cámara.

Recultivo de OPLA-CMM. A la tercera semana de cultivo, el constructo OPLA-CMMg fue sacado de la placa de cultivo y lavado por dos veces con PBS 1X. Luego el constructo fue colocado a cultivar en placa de 24 pocillos, con $1 \mathrm{~mL}$ de medio completo fresco.

Tinción histológica. Para corroborar que en el interior del OPLA había células madres mesenquimales se realizaron cortes histológicos del OPLA. Las muestras fijadas en formalina al $10 \%$ fueron procesadas y teñidas con H-E.

Diferenciación celular en presencia de OPLA. Las CMM en presencia de OPLA fueron diferenciadas de acuerdo a la metodología descrita anteriormente.

\section{RESULTADOS}

Las CMMg obtenidas derivadas de tejido conectivo gingival, fueron caracterizadas según su fenotipo y función, tomando en cuenta los criterios establecidos por la ISCT (Dominici et al.).

El análisis morfológico de CMM en OPLA, a la cuarta semana de cultivo se observan CMMg fuera del OPLA (Fig. 1A), CMMg proliferaron cerca de $70 \%$ de confluencia celular, después de cuatro semanas en cultivo (Fig. 1B). Las CMMg proliferan con un fenotipo similar a fibroblastos (Fig. 1C). El OPLA en cultivo se observa como una andamiaje 3D de celda abierta (Fig. 1D).

La evaluación histológica de cortes teñidos con Hematoxilina Eosina de CMMg en OPLA, reveló que las células se propagan en el interior del constructo. $\mathrm{CMMg}$ mantiene su morfología no diferenciada y fenotipo fibroblastoide (Fig. 2). 


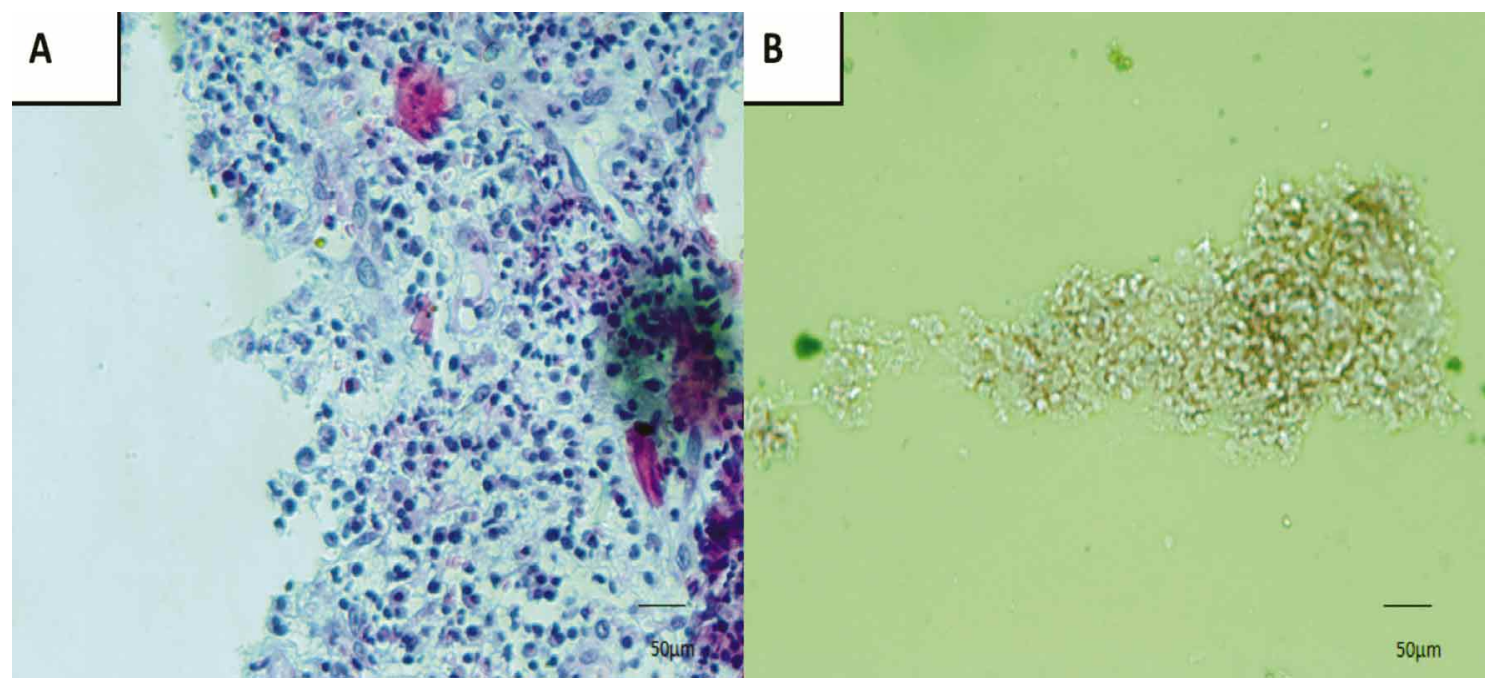

Fig. 2. Cortes histológicos teñidos con Hematoxilina-Eosina. (A) CMMg al interior del OPLA. (B) OPLA solo. Microscopia óptica, magnificación 10X.

Cuando el constructo es recultivado en medio fresco, las células logran proliferar, a partir de la primera semana. Por lo tanto el OPLA es un andamiaje que permite el transporte celular. La viabilidad celular de las CMMg en OPLA fue de $83,32 \%$ (Fig. 3).

Después de 21 días de cultivo celular, los ensayos de diferenciación se evaluaron usando procedimientos estándar.
Para la diferenciación osteogénica, CMMg y OPLA se incubaron durante 21 días en medio de diferenciación y se tiñeron con rojo de alizarina, mostrando la presencia de depósitos de calcio, característicos de una diferenciación osteogénica (Fig. 4A). Para la diferenciación condrogénica, CMMg teñidas con Saphranin O mostraron la formación de una masa condrogénica (Fig. 4B).
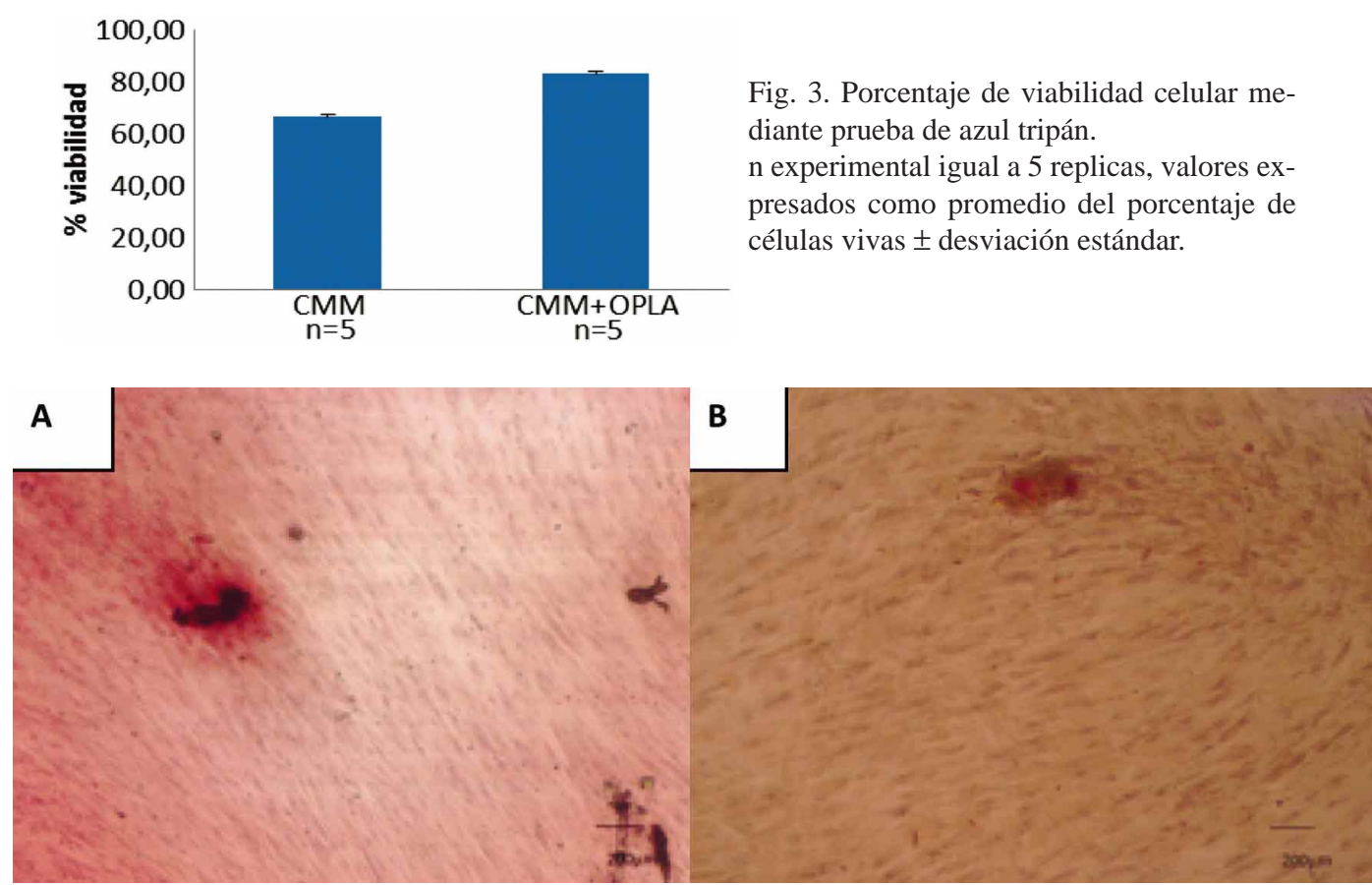

Fig. 4. CMM diferenciadas en presencia de OPLA. (A) CMMg diferenciadas a linaje condrogénico, micromasa teñida de rojo con Safranina O. (B) Diferenciación osteogénica, células teñidas de rojo oscuro con Alizarin Red. Microscopia óptica magnificación 10X. 


\section{DISCUSIÓN}

Para lograr regenerar tejidos se requiere de tres herramientas básicas: células madres, andamiajes y factores de crecimiento. Los andamiajes reemplazan el lugar del tejido perdido, proveen soporte estructural y entregan factores de crecimiento a las células, las cuales se encargan de formar el tejido dañado (Howard et al., 2008). En años recientes se descubrió una nueva fuente de células madres mesenquimales, el tejido conectivo gingival humano (Mitrano et al.; Wada et al., 2011). Una de las ventajas de escoger a este como sitio donante es que es una zona de fácil acceso por lo tanto la muestra se puede obtener sin dificultad, causando un mínimo de morbosidad y molestias al paciente. Es así como la cicatrización de esta zona se caracteriza por una marcada reducción en la inflamación, rápida re-epitelización y no deja cicatrices. Estas células exhiben clonagenicidad, auto renovación, capacidad de diferenciarse en multilinajes, no son tumorogénicas, homogeneidad, alta capacidad proliferativa, presentan morfología estable y no pierden las características de células madres mesenquimales en pasajes avanzados. Tienen propiedades antiinflamatorias e inmunomoduladoras (Zhang et al., 2009; Wang et al., 2011). Es por estas razones que se escogió estudiar la funcionalidad de estas células madres mesenquimales. El uso de un andamiaje tridimensional apropiado debe permitir que las células se le unan, el crecimiento y la diferenciación de éstas. En esta investigación se escogió OPLA (D, D-L, L-ácido poliláctico) un polímero sintético de estructura de celda abierta $3 \mathrm{D}$. Al cultivar CMMg en presencia de OPLA, se observó proliferación celular, lo que sugiere que OPLA es un andamiaje biocompatibles con este tipo celular. Estos resultados concuerdan con los estudios de Gotlieb et al. (2008), donde se observó proliferación de células madres mesenquimales provenientes de dientes temporales exfoliados sembradas en OPLA. En cuanto a la viabilidad de las CMMg al ser sembradas en OPLA nuestros resultados concuerdan con los obtenidos por Alexander et al. $(2007,2008)$. OPLA permite la proliferación celular y no afecta la viabilidad de las CMMg. Los modelos celulares descritos en OPLA muestran que este biomaterial es un buen andamiaje, que proporciona un prometedor ambiente para sustitutos óseos (Alexander et al., 2007). Otro aspecto a considerar es una de las características básicas que debe poseer el andamiaje, este debe permitir el transporte celular. Para analizar este tema se realizó el recultivo de los andamiajes. Los resultados obtenidos sugieren que OPLA conserva CMMg viables que pueden volver a proliferar en medio fresco. En el estudio realizado por Gotlieb et al. también se observa que el andamiaje de OPLA permite el transporte celular, ellos implantaron los constructos al interior de piezas dentarias previamente desinfectadas e instrumentadas, observando proliferación celular al interior del canal. Otra característica importante que debe poseer el biomaterial es permitir la diferenciación celular. Es por esto que se estudió la diferenciación hacia osteoblatos y condroblastos de las CMMg en presencia de OPLA, luego de realizar las tinciones correspondientes se observó diferenciación hacia ambos linajes. OPLA en cultivo mantiene su forma y tamaño durante las cuatro semanas de cultivo. Esto se contrapone con los resultados obtenidos por Gotlieb, en su investigación se observó que el OPLA comienza a reabsorberse a los 14 días de cultivo, no especificando cuando lo hace en forma completa. Esta diferencia se puede deber a que el estudio de Gotlieb et al., lo realizó en dientes desinfectados e instrumentados, los cuales contenían el constructo en su interior, probablemente esta variable fue la causa de los diferentes resultados, aún así se requieren más estudios en esta área.

En conclusión nuestro estudio provee nueva evidencia en relación al OPLA como andamiaje que puede ser utilizado para la regeneración de tejidos ya que es biocompatible con células madres mesenquimales.

BRIZUELA, C. C.; SAINT, J. N. \& INOSTROZA, S. C. Biocompatibility of mesenchymal stem cells derived from human gingival tissue in culture with a scaffold of a synthetic polymer Open Porosity Polylactic Acid Polymer (OPLA). Int. J. Morphol., 32(3):767772, 2014.

SUMMARY: Tissue engineering arises as the ideal treatment for tissue regeneration with the use of scaffolds, stem cells and growth factors. Stem cells derived from gingival tissue present benefits in its objection. 3D OPLA allow high cell density cultures. The objective of this study was to evaluate the biocompatibility of gingival stem cells in OPLA. Cells were obtained from gingival tissue and were characterized phenotypically and functionally. The biocompatibility was evaluated through cell proliferation, viability test with trypan blue and cell differentiation to chondrogenic and osteogenic lineage. Recultivation of the construct was used to evaluate transportability. Cells inside OPLA were visualized by stained sections with H\&E. Mesenchymal stem cells proliferated in OPLA, 80\% confluence at the fourth week. Cell viability in OPLA was $83.32 \%$. In recultivation, cells start proliferating in a week. OPLA allows cell differentiation to chondrogenic and osteogenic lineage. Cells were observed within OPLA. In conclusion OPLA allows proliferation, viability and cell differentiation. OPLA could be used as scaffolds for cells in tissue engineering.

KEY WORDS: Mesenchymal stem cells; Gingival connective tissue; Giocompatibility. 


\section{REFERENCIAS BIBLIOGRÁFICAS}

Alexander, D.; Hoffmann, J.; Munz, A.; Friedrich, B.; Geis-Gerstorfer, J. \& Reinert, S. Comparison of three dimensional scaffolds for bone engineering constructs using human jaw periosteal cells. J. Stem Cells Regen. Med., 2(1):177, 2007.

Alexander, D.; Hoffmann, J.; Munz, A.; Friedrich, B.; Geis-Gerstorfer, J. \& Reinert, S. Analysis of OPLA scaffolds for bone engineering constructs using human jaw periosteal cells. J. Mater. Sci. Mater. Med., 19(3):965-74, 2008.

Bansal, R. \& Bansal, R. Regenerative endodontics: a state of the art. Indian J. Dent. Res., 22(1):122-31, 2011.

Becerra, G. D.; Díaz, Z. J.; Carrión, A. F.; Inostroza, S. C. \& Oyonarte, W. R. Evaluation of mesenchymal stem cell proliferation using different low Intensity pulsed ultrasound intensities. Int. J. Morphol., 30(2):621-6, 2012.

Brizuela, C. C.; Galleguillos, G. S.; Carrión, A. F.; Cabrera, P. C.; Luz, C. P. \& Inostroza, S. C. Isolation and characterization of mesenchymal stem cells from human dental pulp and follicle. Int. J. Morphol., 31(2):739-46, 2013.

Di Felice, V.; Ardizzone, N. M.; De Luca, A.; Marcianò, V.; Marino Gammazza, A.; Macaluso, F.; Manente, L.; Cappello, F.; De Luca, A. \& Zummo, G. OPLA scaffold, collagen I, and horse serum induce an higher degree of myogenic differentiation of adult rat cardiac stem cells. J. Cell Physiol., 221(3):729-39, 2009.

Di Felice, V.; De Luca, A.; Serradifalco, C.; Di Marco, P.; Verin, L.; Motta, A.; Guercio, A. \& Zummo, G. Adult stem cells, scaffolds for in vivo and in vitro myocardial tissue engineering. Ital. J. Anat. Embryol., 115(1-2):65-9, 2010.

Dominici, M.; Le Blanc, K.; Mueller, I.; Slaper-Cortenbach, I.; Marini, F.; Krause, D.; Deans, R.; Keating, A.; Prockop, D. \& Horwitz, E. Minimal criteria for defining multipotent mesenchymal stromal cells. The International Society for Cellular Therapy position statement. Cytotherapy, 8(4):315-7, 2006

Friedlander, L. T.; Cullinan, M. P. \& Love, R. M. Dental stem cells and their potential role in apexogenesis and apexification. Int. Endod. J., 42(11):955-62, 2009.

Gotlieb, E. L.; Murray, P. E.; Namerow, K. N.; Kuttler, S. \& GarciaGodoy, F. An ultrastructural investigation of tissue-engineered pulp constructs implanted within endodontically treated teeth. J. Am. Dent. Assoc., 139(4):457-65, 2008.

Howard, D.; Buttery, L. D.; Shakesheff, K. M. \& Roberts, S. J. Tissue engineering: strategies, stem cells and scaffolds. J. Anat., 213(1):66$72,2008$.

Kaigler, D.; Cirelli, J. A. \& Giannobile, W. V. Growth factor delivery for oral and periodontal tissue engineering. Expert Opin. Drug Deliv., 3(5):647-62, 2006.

Linnes, M. P.; Ratner, B. D. \& Giachelli, C. M. A fibrinogen-based precision microporous scaffold for tissue engineering. Biomaterials, 28(35):5298-306, 2007.

Mitrano, T. I.; Grob, M. S.; Carrión, F.; Nova-Lamperti, E.; Luz, P. A.; Fierro, F. S.; Quintero, A.; Chaparro, A. \& Sanz, A. Culture and characterization of mesenchymal stem cells from human gingival tissue. J. Periodontol., 81(6):917-25, 2010.

Qian, X.; Villa-Diaz, L. G. \& Krebsbach, P. H. Advances in culture and manipulation of human pluripotent stem cells. J. Dent. Res., 92(11):956-62, 2013.

Zhang, Q.; Shi, S.; Liu, Y.; Uyanne, J.; Shi, Y.; Shi, S. \& Le, A. D. Mesenchymal stem cells derived from human gingiva are capable of immunomodulatory functions and ameliorate inflammationrelated tissue destruction in experimental colitis. J. Immunol., 183(12):7787-98, 2009.

Rekow, D. Informatics challenges in tissue engineering and biomaterials. Adv. Dent. Res., 17:49-54, 2003.

Scheller, E. L.; Krebsbach, P. H. \& Kohn, D. H. Tissue engineering: state of the art in oral rehabilitation. J. Oral Rehabil., 36(5):36889, 2009.

Saber, S. E. Tissue engineering in endodontics. J. Oral Sci., 51(4):495507, 2009.

Thomson, A. \& Kahler, B. Regenerative endodontics--biologically-based treatment for immature permanent teeth: a case report and review of the literature. Aust. Dent. J., 55(4):446-52, 2010.

Tokalov. S. V.; Gruener, S.; Schindler, S, Iagunov, A. S.; Baumann, M. \& Abolmaali, N. D. A number of bone marrow mesenchymal stem cells but neither phenotype nor differentiation capacities changes with age of rats. Mol. Cells, 24(2):255-60, 2007.

Wada, N.; Wang, B.; Lin, N. H.; Laslett, A. L.; Gronthos, S. \& Bartold, P. M. Induced pluripotent stem cell lines derived from human gingival fibroblasts and periodontal ligament fibroblasts. $J$. Periodont. Res., 46(4):438-47, 2011.

Wang, F.; Yu, M.; Yan, X.; Wen, Y.; Zeng, Q.; Yue, W.; Yang, P. \& Pei, $\mathrm{X}$. Gingiva-derived mesenchymal stem cell-mediated therapeutic approach for bone tissue regeneration. Stem Cells Dev., 20(12):2093102,2011

Yen, A. H. \& Yelick, P. C. Dental tissue regeneration - a mini-review. Gerontology, 57(1):85-94, 2011.

\section{Dirección para Correspondencia: \\ Bq. Carolina Inostroza Silva \\ Profesor Asistente Extraordinario \\ Facultad de Odontología \\ Mons. Álvaro del Portillo 12.455, Las Condes \\ Universidad de los Andes \\ Santiago \\ CHILE}

Email:caroviriffo@gmail.com

Recibido : 20-01-2014 Aceptado: 10-06-2014 